\title{
The Effect of Basic Movement Skills Education Using the Differential Learning Approach on Attention and Motoric Features of Elementary School Students
}

\author{
Farklııkla Öğrenme Yaklaşımı ile Uygulanan \\ Temel Hareket Becerileri Eğitiminin Ilkokul \\ Öğrencilerinin Dikkat ve Motorik Özelliklerine Etkisi
}

\author{
Nuri Topsakal (iD) https://orcid.org/0000-0003-1583-107X \\ Spor Bilimleri Fakültesi, Düzce Üniversitesi, Düzce, Türkiye
}

\begin{abstract}
Sinan Bozkurt ${ }^{1}$ (iD) https://orcid.org/0000-0002-9138-565X
Spor Bilimleri Fakültesi, Marmara Üniversitesi, İstanbul, Türkiye
\end{abstract}

Hüseyin Akın (Dhttps://orcid.org/0000-0001-9382-8373

Universitat Hamburg, Institut für Bewegungswissenschaft, Hamburg, Almanya

Received: 17.06.2019

Accepted: 16.09.2019

Online Published: 30.09.2019

DOI: $10.30655 /$ besad.2019.19

https//:doi.org/10.30655/besad.2019.19

\begin{abstract}
The purpose of this study was to investigate the effect of differential learning approach on attention and motor skills of elementary school students through basic movement skills education program. Total 20 students aged 9-10 years in the third grade of an elementary school in Beykoz, Istanbul participated in this study. 12 of them were boys $(132,75 \pm 7,38 \mathrm{~cm}$. of height, $31,50 \pm 9,57 \mathrm{~kg}$. of body weight) and eight of them were girls $(131,95 \pm 6,19 \mathrm{~cm}$., 33,57 $\pm 8,19 \mathrm{~kg}$. of body weight) The Basic Movement Skills program on the Yellow Cards group of the Physical Activity Cards (PAC) prepared for the "Games and Physical Activities" classes was carried out with perspective of differential learning on the experimental group during 4 course hour for 10 weeks. "Bourdon Attention Test", "Illinois Agility Test", 10 and 20 m. Sprint Tests", "Flamingo Balance Test", "Standing Long Jump Test (STJ)", "Sit-up Test" were carried out as a pre-test in the beginning of the study period and as and post-test at the end. The data collected were determined as descriptive statistics and according to the result of the Wilcoxon Signed-Rank Test, it was seen that there was a significant
\end{abstract}

\footnotetext{
${ }^{1}$ Corresponding author: Sinan Bozkurt

Marmara Üniversitesi, Spor Bilimleri Fakültesi, Anadoluhisarı Yerleşkesi, 34380 Beykoz, İstanbul. sbozkurt@marmara.edu.tr
} 
statistical difference between the pre-test and post-test points of the Attention $(p<0.01), 10 \mathrm{~m}$. sprint $(p<0.01), 20 \mathrm{~m}$. sprint ( $p<0.01)$ features of the students of the experimental group and that these features were improved for the better and there was a significant statistical difference between the pre-test and post-test points of the according to the data collected, it was evaluated that the Basic Movement Skills practices with differential learning approach can be effective on the attention and speed improvements of $3^{\text {th }}$ grade elementary school students.

Keywords: Differential learning, movement skills, attention, physical activities, motoric features.

\section{Öz}

Bu çalışmanın amacı, farklııkla öğrenme yaklaşımı ile uygulanan temel hareket becerileri eğitimi programının, ilkokul ögrencilerinin dikkat ve motorik özelliklerinin gelişimi üzerindeki etkilerini araştırmaktır. Çalışma grubunu istanbul

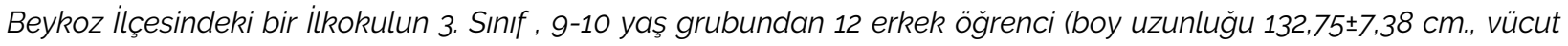

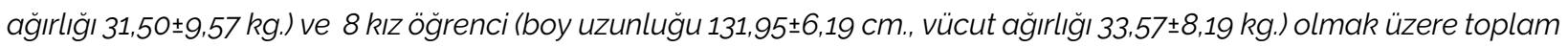
20 öğrenci oluşturmuştur. Bu araştırmada çalışma grubuna farklılıkla öğrenme yaklaşımı ile haftada 2 gün ve 4 ders saati olmak üzere 10 hafta süresince "Oyun ve Fiziki Etkinlikler" dersleri için hazırlanmış olan Fiziksel Etkinlik Kartları ndan Sarı Kart grubundaki, Temel Hareket Becerileri alanı olan programı uygulanmıştır. Çalışmada ön test ve son test olarak "Bourdon dikkat testi", "Çeviklik testi", "10 m. ve 20 m. koşu sürati testleri", "Flamingo denge testi", "Durarak uzun atlama testi", "Mekik testi" yapılmıştır. Elde edilen veriler, tanımlayıcı istatistikler olarak belirlenmiş ve Wilcoxon işaretli sıralar toplamı testi sonucuna göre de deney grubu ögrencilerinin Dikkat ( $p<0.01), 10 \mathrm{~m}$. koşu ( $p<0.01$ ), $20 \mathrm{~m}$. koşu ( $p<0.01)$ özelliklerinin ön ve son test puanları arasında istatistiksel açıdan anlamlı bir fark olduğu ve bu özelliklerin olumlu yönde gelişstiği saptanmışır. Elde edilen verilere göre farklııkla öğrenme yaklaşımı ile uygulanan temel hareket beceri eğitimi uygulamalarının 3. sını filkokul öğrencilerinin özellikle dikkat ve sürat özelliklerinin gelişimi üzerine etkili olabileceği değerlendirilmiştir.

Anahtar kelimeler: Farklılıkla öğrenme, hareket becerisi, dikkat, fiziksel aktivite, motorik özellik.

\section{Giriș}

Fiziksel ya da spor etkinliklerinin çocukların bilişsel, duyuşsal, psikomotor özelliklerinin gelişimine olumlu yönde etki ettiği bildirilmektedir (Lapointe, 2016; Bozkurt ve vd., 2016; Yin \& Moore, 2004; Hürmeriç, 2003). Fiziksel aktivite, enerjiyi harcamak için vücudun hareket etmesi olarak tanımlanmaktadır. Temel vücut hareketlerinin tümünü ya da bir kısmını içeren çeşitli spor dalları, dans, egzersiz, oyun ve gün içerisindeki aktiviteler fiziksel aktivite olarak kabul edilebilirler. Egzersiz ise düzenli olarak yapılan ve vücut hareketlerini içeren fiziksel aktivitedir (American College of Sports Medicine, 2013). Fiziksel aktiviteye katılımın artırıması ve sürdürülebilirliği yönünden okullardaki oyun ve fiziki etkinlikler ve beden eğitimi ve spor derslerinin önemli bir fırsat olduğu değerlendirilebilir.

Millî Eğitim Bakanlığı (MEB) Talim ve Terbiye Kurulu Başkanlığı (TTKB) 2012-2013 eğitim - öğretim yılından itibaren 1. sınıftan başlamak ve kademeli olarak üst sınıflarda uygulanmak üzere kabul ettiği ilkokul Oyun ve Fiziki Etkinlikler (OFE) dersi öğretim programını için Uluslararası İham Projesi kapsamında Fiziksel Etkinlik Kartları (FEK) hazırlanmıştır. (MEB, 2012a; MEB, 2012b). Bu bağlamda, oyun ve beden eğitimi aracılığıyla öğrencilerin psikomotor, bilişsel, duyuşsal gelişimleri yönünden katkı sağlanması amaçlanmaktadır.

İrez ve diğerleri (2013) tarafından da Fiziksel Etkinlik Kartları (FEK) nın beden eğitimi derslerinde beceri gelişimi için oldukça kullanılır bir materyal olduğunu belirtilmişsir. Dikkat, uyaranların farkında olan sinir sisteminin bir işlevi olarak tanımlanabilir. Dikkat toplama, istek üzerine bilincimizin bir konu üzerine toplanması halidir. Etkili ve kalıcı öğrenmenin gerçekleşmesi, amaçlarımıza uygun hareket edebilmek, etkinliklerimizi amaçlarımız doğrultusunda düzenleyebilmek açısından özel bir öneme sahiptir. Dikkat toplamada yeteneklerin ve çalışma şeklinin de etkisi vardır (Amado, 1996; Özdoğan, 1999; Karaduman, 
2004: Lauth, 2004). Dikkat toplama becerisinin çocukluk yıllarında bilişsel, sosyal ve duygusal gelişim ve öğrenme süreci için bir ön koşul olduğu bilinmektedir (Demir, 2009; Konrad \& Gilsbach, 2007). Yurdakul ve diğerleri (2012) beden eğitimi derslerinde dikkat ve hafıza gelişimine yol açabilecek, temel hareket ve hareket örüntülerine dayanan planlanmış oyun ve benzeri etkinlikler oldukça yararlı olabildiği ve bu sayede çocukların algılama, dikkat ve hafızada tutabilme yetilerinin artmakta olduğunu bildirmektedir.

Farklııkla öğrenme yaklaşımında, bir eğitmenin verdiği hareket görevlerinin devamlı değişkenlik, çeşitlilik göstermesi önemlidir. Bu şekilde bireyin, oluşan yeni, ani ve sürpriz durumlara mümkün olduğu kadar çabuk uyum sağlayabilmesi amaçlanır. Klasik antrenman yöntemlerinde olduğu gibi, birbiri ardına gelen hareket uygulamalarında aynı şekilde çok tekrar yerine, farklııkla öğrenme yaklaşımında tekrarların çeşitlilik göstermesi ve harekete özgü tekniğinin mükemmel yapılmasından ziyade dikkatin tekniğin temeline verilerek uygulanması önem taşır. Klasik antrenman yöntemlerindeki hata değerlendirmeleri, farklılıla öğrenme yaklaşımında doğal oluşan farklılılar olarak değerlendirilir. Farklııkla öğrenme yaklaşımına göre eğitmenlerin klasik yöntemdeki gibi bireyin yaptığı hatayı ikaz edip düzeltmeyi benimsemesi uygulayıcının motorik çözümler bulabilmesini zorlaştııır. Oysaki yapılan hata değerlendirmeleri sırasında doğal oluşan farklııklar, kişiye özel uygulama varyasyonları ve dalgalanmaları olarak görülür. Bu dalgalanmalara makul çerçeve içinde olmak şartı ile müsaade etmenin, kişinin yeni çözümler bulmasına fırsat tanıdığı değerlendirilir. Bireyin ortam şartlarının değişimine uyum sağlayabilmesi, sürpriz ve ani durumları motorik-teknik olarak çözebilmesi ve bu başarı duygusundan dolayı salgılanan dopaminin de öğrenme sürecini olumlu etkilediği bildirilmektedir (Schöllhorn, 2015; Schöllhorn vd., 2012; Schöllhorn vd., 2009).

Farklııkla öğrenme yaklaşımının hareket becerilerinin öğrenimini olumlu yönde etkilediği, hareket becerilerinin de dikkat yetisi için yararlı olabileceği bildirilmektedir. Bu bağlamda, araştırmamızın problem cümlesini farklılıkla öğrenme yaklaşımının dikkat ve motorik özelliklerin gelişimine etkisi var mıdır? sorusu oluşturmuştur. Bu çalışmanın amacı, oyun ve fiziki etkinlikler dersinde kullanılan Farklııkla öğrenme yaklaşımı ile gerçekleştirilen temel hareket beceri eğitimi çalışmalarının ilkokul 3. sınıf öğrencilerinin dikkat ve motorik özelliklerinin gelişimine etkisini araştırmaktır.

\section{Yöntem}

\section{Araştırmanın Modeli}

Araştırma deneysel modellerden tek gruplu ön test-sontest modeline göre düzenlenmiştir. Deneysel araştırmalar, araştırmacının uygulayacağı programın (bağımsız değişken- farklılıkla öğrenme yaklaşımı ile uygulanan temel hareket becerileri eğitimi) çalışma grubunun belirlenen özellikleri (bağımlı değişken-motorik ve dikkat özellikleri) üzerindeki etkisini incelemek için kullanılır (Campbel \& Stanley, 1963).

\section{Çalışma Grubu}

Bu araştırmada çalışma grubunu İstanbul ili Beykoz ilçesindeki bir ilkokulun 3. sınıftaki 9 yaş grubundan

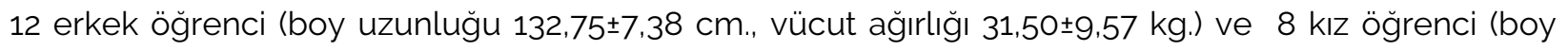

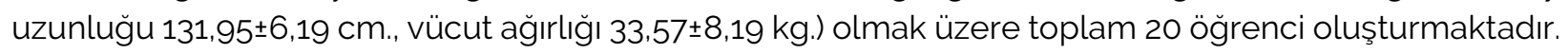

\section{Veri Toplama Araçları}

Çalışma grubunun fiziksel özelliklerinin belirlenmesi için boy uzunluğu, vücut ağırlığı ölçümleri yapılmış ve vücut kütle indeksi değerleri hesaplanmıştır. Öğrencilerin motorik özelliklerin belirlenmesi için 10 
m. ve 20 m. koşu sürati testleri, çeviklik testi (zigzag), Eurofit bataryası testlerinden durarak uzun atlama testi, flamingo denge testi, mekik testi (Committee of Experts on Sports Research, 1988) ile dikkat özelliğinin ölçümünde veri aracı olarak Bourdon dikkat testi kullanılmıştır. Bourdon testinin amacı bireylerin dikkat düzeylerini ölçmektir. Bireylere bir sayfa üzerine gelişi güzel dizilmiş harfler verilir. Bu harfler belli ve düzenli aralıklarla dizilmiştir. Her sayfada 407 harf bulunur. Her sayfada da 20 satır vardır. Sayfadaki her harfin sayısı bilinir. Deneme için hazırlanan yaprakta 150 tane (a), 75 tane (g), 50 tane (b) ve 25 tane (d) harfi vardır. Bourdon denemesinde 9-20 yaşları arasındaki bireylere uygulanır. Bireye "Önünüzdeki sayfada bulunan bütün $\mathrm{a}$, b, d ve g harflerinin altlarını kurşun kalemle çizeceksiniz. Bir satırı gözden geçirirken yalnız bir harfi işaretlemeyeceksiniz. Satırdaki tüm a, b, d ve g harflerinin altını çizeceksiniz" şeklinde yönerge verilir ve testin değerlendirilmesi çizgiler sayılarak yapılır. Testin değerlendirilmesinde, çocukların verdiği doğru cevaplar dikkate alınır. Her doğru cevap bir puan olarak kabul edilir (Brickenkamp ve vd. den aktaran Göktepe,2016). Her bir bölüm için puanlar ayrı ayrı kaydedilerek Bourdon Dikkat Testi'nin geçerlik ve güvenirlik çalışması 4. ve 5. sınıf öğrencilerinden oluşan toplam 150 öğrenciye 15 gün ara ile test tekrar uygulanarak yapılmış, iki değerlendirme arasındaki korelasyon katsayısı. 78 olarak bulunmuştur (Karaduman'dan aktaran Göktepe, 2016). Çalışmada üç bölümden oluşan dikkat testinin puanları, her bir bölüm için ve üç bölümün genel toplam puanı olmak üzere kaydedilmiştir.

\section{Uygulama Süreci}

Çalışma grubuna fiziksel etkinlik kartlarında yer alan etkinlikler 2017-2018 eğitim öğretim yılı oyun ve fiziki etkinlikler dersinde haftada iki gün ve toplam dört ders saati olmak üzere 10 hafta süresince uygulanmıştır. Fiziksel etkinlik kartlarında (sarı kartlar) yer alan konular farklılıla öğrenme yaklaşımına göre rutin tekrarların olmadığı, düzeltici dış geri bildirimin verilmediği uygulama çeşitliliği ile yaptırılmıştır. Her bir çalışma ısınma, esas ve soğuma devrelerine ayrıldı. Çalışma kapsamında, iki bölüme ayrılan esas devrenin birinci bölümünde yer değiştirme ve dengeleme hareketlerinden yürüme, koşma, atlama, adımlama, kayma, eğilme, çömelme, yuvarlanma, dönme, salınım, ağılık aktarımı, atlama-konma, başlama-durma, dinamik-statik denge, duruş-oturuş, itme-çekme çalışmaları yapıldı. İkinci bölümünde ise nesne kontrolü gerektiren ve birleştirilmiş hareketlerden seçilen çalışma başlıkları oyun formunda uygulandı. Çeşitlendirmeler; beton, parke, minder zeminlerde, küçük-büyük alanlarda, farklı boyut ve türlerde ekipman (top, atlama ipi, denge tahtası vb.) kullanılarak, kapalı-açık beceri koşullarında, bireysel, eşli, grup çalışmaları şeklinde yapıldı.

\section{Verilerin Çözümlenmesi}

Tanımlayıcı istatistik olarak aritmetik ortalama (X), standart sapma (Ss), en küçük (Min.) ve en büyük (Maks.) değerleri belirtilmiş, deney grubunun ön ve son test değerleri arasındaki farklılıların belirlenmesi için ise Wilcoxon testi kullanımıştır. Anlamlıık düzeyi $p<0.05$ olarak belirlenmiştir.

\section{Bulgular}

Tablo 1'de çalışma grubu öğrencilerinin fiziksel özelliklerinin tanımlayıcı istatistikleri verilmiştir. Boy uzunluğu (cm.) ön test- son test $(132,27 \pm 6,51-133,77 \pm 6,85)$, vücut ağırlığı (kg.) ön test- son test $(32,74 \pm$ $8,58-33,27 \pm 8,47)$, beden kütle indeksi $(\mathrm{kg} / \mathrm{m})$ ön test- son test $(18,49 \pm 3,57-18,38 \pm 3,41)$ olarak ölçülmüştür.

Çeviklik (sn.) ön test- son test $(8,48 \pm, 68-8,38 \pm, 65), 10 \mathrm{~m}$. sürat (sn.) ön test- son test $(2,58 \pm, 19-2,43 \pm, 15)$, 20 m. sürat (sn.) ön test- son test $(4,74 \pm, 38-4,53 \pm, 32)$, denge (hata sayısı) ön test- son test $(11,55 \pm 3,72-$ $12,35 \pm 4,09$ ), durarak uzun atlama (cm.) ön test- son test $(111,40 \pm 16,22-116,15 \pm 15,22)$, mekik (tekrar) ön test- son test $(11,75 \pm 5,63-13,80 \pm 5,00)$ olarak ölçülmüştür. 
Tablo 1. Öğrencilerinin Fiziksel Özellik Ölçümlerinin Tanımlayııı İstatistikleri

\begin{tabular}{llccccc}
\hline & & N & Min & Maks. & X & Ss \\
\hline \multirow{2}{*}{ Boy Uzunluğu (cm.) } & Ön Test & 20 & 122,00 & 144,50 & 132,27 & 6,51 \\
& Son Test & 20 & 124,00 & 146,00 & 133,77 & 6,85 \\
\multirow{2}{*}{ Vücut Ağırlığı (kg.) } & Ön Test & 20 & 21,30 & 51,20 & 32,74 & 8,58 \\
& Son Test & 20 & 21,50 & 50,30 & 33,27 & 8,47 \\
Beden Kütle & Ön Test & 20 & 13,98 & 25,22 & 18,49 & 3,57 \\
Indeksi(kg/m) & Son Test & 20 & 13,60 & 24,50 & 18,38 & 3,41 \\
\cline { 2 - 5 } & & & &
\end{tabular}

Dikkat testi; bölüm 1 ön test - son test $(30,95 \pm 6,25$ - 34,30 $\pm 4,47$ puan), bölüm 2 ön test- son test $(34,60 \pm 4,81-37,50 \pm 2,37$ puan), bölüm 3 ön test- son test $(32,55 \pm 4,00-34,75 \pm 1,58$ puan) ve genel

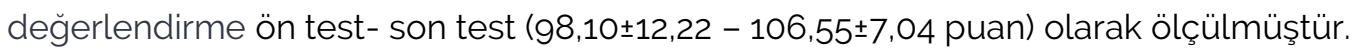

Çalışma grubu öğrencilerinin motorik özelliklerinin öntest ve sontestte anlamlı bir farklılık gösterip göstermediğine ilişkin Wilcoxon işaretli sıralar testi sonuçları Tablo 4'te verilmiştir. Çalışma grubunun $10 \mathrm{~m}$. sürat $(Z=-3,248 ; p<.001), 20 \mathrm{~m}$. sürat $(Z=-3.361 ; p<.001)$ özelliklerinin ön ve son test sonuçları arasında son test grubu lehine istatistiksel açıdan anlamlı bir fark vardır.

Öğrencilerin 10 m. sürat (\% 5,82) ve 20 m. sürat (\% 4,44) ortalama değerlerinde artış belirlenmiştir. Çalışma grubunun çeviklik ( $Z=-.653 ; p>.514)$, denge $(Z=-1,229 ; p>.219)$, durarak uzun atlama $(Z=-1,288$; $p>$.198) ve mekik ( $Z=-1,947 ; p>$.051), özelliklerinin ön ve son test sonuçları arasında istatistiksel açıdan anlamlı bir fark yoktur. Çalışma grubu öğrencilerinin dikkat özelliklerinin öntest ve sontestte anlamlı bir farklıık gösterip göstermediğine ilişkin Wilcoxon işaretli sıralar testi sonuçları Tablo 5 'te verilmiştir:

Tablo 2. Öğrencilerinin Motorik Özellik Test Ölçümlerinin Tanımlayıcı İstatistikleri

\begin{tabular}{lllllll}
\hline & & N & Min & Maks. & X & Ss \\
\hline \multirow{2}{*}{ Çeviklik (sn) } & Ön Test & 20 & 7,46 & 10,00 & 8,48 &, 68 \\
& Son Test & 20 & 7,18 & 9,69 & 8,38 &, 65 \\
\multirow{2}{*}{10 m. Sürat (sn) } & Ön Test & 20 & 2,27 & 2,94 & 2,58 &, 19 \\
& Son Test & 20 & 2,17 & 2,77 & 2,43 &, 15 \\
\multirow{2}{*}{ 20 m. Sürat (sn) } & Ön Test & 20 & 4,23 & 5,48 & 4,74 &, 38 \\
& Son Test & 20 & 3,98 & 5,06 & 4,53 &, 32 \\
Denge (hata sayısı) & Ön Test & 20 & 4,00 & 15,00 & 11,55 & 3,72 \\
\multirow{2}{*}{ Durarak Uzun Atlama } & Son Test & 20 & 4,00 & 19,00 & 12,35 & 4,09 \\
(cm) & Ön Test & 20 & 85,00 & 142,00 & 111,40 & 16,22 \\
Mekik (tekrar) & Son Test & 20 & 87,00 & 151,00 & 116,15 & 15,22 \\
& Ön Test & 20 &, 00 & 19,00 & 11,75 & 5,63 \\
& Son Test & 20 & 1,00 & 20,00 & 13,80 & 5,00 \\
\hline
\end{tabular}


Tablo 3. Öğrencilerinin Bourdon Dikkat Testi Ölçümlerinin Tanımlayıcı İstatistikleri

\begin{tabular}{|c|c|c|c|c|c|c|}
\hline & & $\mathrm{N}$ & Min & Maks. & $x$ & Ss \\
\hline Bourdon Dikkat Testi & Ön Test & 20 & 16,00 & 38,00 & 30,95 & 6,25 \\
\hline 1. Bölüm (puan) & Son Test & 20 & 21,00 & 38,00 & 34,30 & 4,47 \\
\hline Bourdon Dikkat Testi & Ön Test & 20 & 25,00 & 40,00 & 34,60 & 4,81 \\
\hline 2. Bölüm (puan) & Son Test & 20 & 32,00 & 40,00 & 37,50 & 2,37 \\
\hline Bourdon Dikkat Testi & Ön Test & 20 & 19,00 & 36,00 & 32,55 & 4,00 \\
\hline 3. Bölüm (puan) & Son Test & 20 & 30,00 & 36,00 & 34,75 & 1,58 \\
\hline $\begin{array}{l}\text { Bourdon Dikkat Testi } \\
\text { Genel Değerlendirme }\end{array}$ & Ön Test & 20 & 75,00 & 114,00 & 98,10 & 12,22 \\
\hline 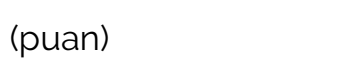 & Son Test & 20 & 86,00 & 114,00 & 106,55 & 7,04 \\
\hline
\end{tabular}

Tablo 4. Motorik Özellikler Öntest ve Sontest Toplam Puanlarının Wilcoxon İşaretli Sıralar Testi

\begin{tabular}{|c|c|c|c|c|c|c|}
\hline & & $\mathrm{n}$ & $\begin{array}{c}\text { Sıra } \\
\text { Ortalaması }\end{array}$ & $\begin{array}{c}\text { Sıra } \\
\text { Toplamı }\end{array}$ & z & $\mathrm{p}$ \\
\hline \multirow{3}{*}{ Çeviklik (sn) } & Negatif sıra & 12 & 10,21 & 122,50 & & \\
\hline & Pozitif Sıra & 8 & 10,94 & 87,50 &,- 653 & .514 \\
\hline & Eşit & 0 & & & & \\
\hline \multirow{3}{*}{10 m. Sürat (sn) } & Negatif sıra & 17 & 11,29 & 192,00 & & \\
\hline & Pozitif Sıra & 3 & 6,00 & 18,00 & $-3,248$ &, $001^{*}$ \\
\hline & Eşit & 0 & & & & \\
\hline \multirow{3}{*}{20 m. Sürat (sn) } & Negatif sıra & 16 & 12,19 & 195,00 & & \\
\hline & Pozitif Sıra & 4 & 3.75 & 15,00 & $-3,361$ &, $001^{*}$ \\
\hline & Eşit & 0 & & & & \\
\hline \multirow{3}{*}{ Denge (hata sayısı) } & Negatif sıra & 4 & 8,25 & 33,00 & & \\
\hline & Pozitif Sıra & 10 & 7,20 & 72,00 & $-1,229$ & ,219 \\
\hline & Eşit & 6 & & & & \\
\hline \multirow{3}{*}{$\begin{array}{l}\text { Durarak Uzun } \\
\text { Atlama (cm) }\end{array}$} & Negatif sıra & 8 & 8,81 & 70,50 & & \\
\hline & Pozitif Sıra & 12 & 11,63 & 139.50 & $-1,288$ & 198 \\
\hline & Eşit & 0 & & & & \\
\hline \multirow{3}{*}{ Mekik (tekrar) } & Negatif sıra & 6 & 8,83 & 53,00 & & \\
\hline & Pozitif Sıra & 14 & 11,21 & 157,00 & $-1,947$ & .051 \\
\hline & Eşit & 0 & & & & \\
\hline
\end{tabular}


Tablo 5. Dikkat Özelliği Öntest ve Sontest Toplam Puanlarının Wilcoxon İşaretli Sıralar Testi Sonuçları

\begin{tabular}{|c|c|c|c|c|c|c|}
\hline & Sontest-Öntest & $n$ & $\begin{array}{c}\text { Sıra } \\
\text { Ortalaması }\end{array}$ & $\begin{array}{c}\text { Sıra } \\
\text { Toplamı }\end{array}$ & z & $\mathrm{p}$ \\
\hline \multirow{3}{*}{$\begin{array}{l}\text { Bourdon } \\
\text { Dikkat Testi } \\
\text { 1. Bölüm }\end{array}$} & Negatif sıra & 3 & 5,83 & 17.50 & & \\
\hline & Pozitif Sıra & 15 & 10,23 & 153,50 & $-2,969$ & $.003^{*}$ \\
\hline & Eşit & 2 & & & & \\
\hline \multirow{3}{*}{$\begin{array}{l}\text { Bourdon } \\
\text { Dikkat Testi } \\
\text { 2. Bölüm }\end{array}$} & Negatif sıra & 2 & 3,00 & 6,00 & & \\
\hline & Pozitif Sıra & 13 & 8,77 & 114,00 & $-3,083$ & $.002^{*}$ \\
\hline & Eşit & 5 & & & & \\
\hline \multirow{3}{*}{$\begin{array}{l}\text { Bourdon } \\
\text { Dikkat Testi } \\
\text { 3. Bölüm }\end{array}$} & Negatif sıra & 2 & 3,25 & 6,50 & & \\
\hline & Pozitif Sıra & 12 & 8,21 & 98,50 & $-2,909$ & $.004^{*}$ \\
\hline & Eşit & 6 & & & & \\
\hline \multirow{3}{*}{$\begin{array}{l}\text { Bourdon } \\
\text { Dikkat Testi } \\
\text { Genel } \\
\text { Değerlendirme }\end{array}$} & Negatif sıra & 2 & 3.50 & 7,00 & & \\
\hline & Pozitif Sıra & 16 & 10,25 & 164,00 & $-3,421$ &, $001^{*}$ \\
\hline & Eşit & 2 & & & & \\
\hline
\end{tabular}

Çalışma grubu öğrencilerinin Dikkat Testi; Bölüm 1 ( $Z=-2,969 ; p<.003), \quad$ Bölüm 2 ( $Z=-3,083 ; p<.002)$, Bölüm 3 ( $Z=-2,909 ; p<.004)$, ve Genel Değerlendirme $(Z=-3.421 ; p<.001)$ ön ve son test puanları arasında istatistiksel açıdan son test grupları lehine anlamlı bir fark vardır.

\section{Tartışma ve Sonuç}

Bu araştırma temel hareket beceri eğitiminde farklılıkla öğrenme yaklaşımının ilkokul 3. sınıf öğrencilerinin dikkat ve motorik özelliklerine etkisi yönünden değerlendirilmesi amacıyla yapılmıştır. Yapılan 10 haftalık çalışma sonucunda, öğrencilerin $10 \mathrm{~m}$. sürat, $20 \mathrm{~m}$. sürat özelliklerinin ön ve son test sonuçları arasında son test grubu lehine istatistiksel açıdan anlamlı bir fark olduğu $(p<0.01)$ ve bu özelliklerin olumlu yönde geliştiği belirlenmiştir. Tohumat ve Arabacı (2017) tarafından 12 haftalık sürede halk oyunları eğitimine katılan ve katılmayan 7-9 yaş grubu öğrencilerin, $30 \mathrm{~m}$. sürat testi ön ve son test ölçümleri yapılmıştır. $30 \mathrm{~m}$. sürat ön ve son testleri sonuçları arasında eğitime katılan öğrencilerde istatistiksel olarak anlamlı farklılık bulunmuştur. Bozkurt ve diğerleri (2016) FEK denge hareketleri programının 9 yaş grubu ilkokul öğrencilerinin sprint gelişimleri üzerine etkili olabileceğini bildirmiştir. Çocukların sürat koşularına 7 yaşından itibaren başlamaları gerektiği, hareket süratlerinde 7-10 yaş grubunda keskin bir artış olacağı ve özellikle 10 yaşında doruk noktasına ulaşacağı ileri sürülmektedir (Portmann, Hanh' dan aktaran Özbar, 2018).

Gerçekleştirilen bu çalışmamızda da benzer bulgulara ulaşılmıştır. Buna göre 7-10 yaş grubu çocukların fiziksel aktiviteye katılımının sürat özelliğinin gelişimine olumlu yönde katkı sağlayacağı değerlendirilebilir. Çalışma sonucunda, öğrencilerin çeviklik özelliği ön ve son test sonuçları arasında istatistiksel açıdan anlamlı bir fark bulunmamıştır. Alesi ve diğerleri (2016) 6 ay futbol antrenmanı yapan çocukların (yaş=8.8 yıl) çeviklik ölçümlerinde anlamlı düzeyde bir artış olduğunu, Yıldız (2013) sekiz hafta 
süresince, haftanın 3 günü fonksiyonel antrenman yapan tenisçi çocukların (yaş=9,6 yıl, spor yaşı=3,1 yıl) çeviklik özelliklerinin istatistiksel olarak anlamlı bir artış gösterdiğini bildirmektedir.

Çalışma bulgularımız diğer araştırma sonuçlarıyla örtüşmemektedir. Bu farklıığın çalışmamızdaki eğitim-antrenman süresinin ve öğrencilerin antrenmana katılım dönemlerinin (spor yaşı) daha az olmasından kaynaklanabileceği değerlendirilmektedir. Çalışmamızın sonucunda, öğrencilerin denge, durarak uzun atlama ve mekik özellikleri ön ve son test sonuçları arasında istatistiksel açıdan anlamlı bir fark bulunmamıştır. Güneş (2019) 8-10 yaş grubu çocuklarda haftada 3 gün 8 hafta boyunca yapılan kayak temel eğitiminin denge üzerine olumlu etkisi olduğunu bildirmektedir. Dinçer ve diğerleri (2017) 8 haftalık sağlık topu egzersizi yapan 10-12 yaş grubu yüzücülerin kuvvet özelliklerinde (mekik, durarak uzun atlama testleri) gelişme olduğunu bildirmiştir. Yılmaz ve Bozkurt (2016) tarafından yapılan çalışmada 6 haftalık oyun ve fiziki etkinlikler ders uygulaması sonrasında 9-10 yaş öğrencilerin durarak uzun atlama $(\% 1,55)$ ve mekik $(\%$ 13,86) ortalama değerlerinde artış belirlenmiştir.

Bizim çalışmamızın sonucunda ise öğrencilerin durarak uzun atlama (\% 4,08) ve mekik (\% 14,85) ortalama değerlerinde gelişme olsa da bu istatistiksel olarak anlamlı düzeyde değildir. Buna göre on hafta süresince, haftanın 2 günü farklııkla öğrenme yaklaşımına göre yapılan fiziksel etkinliklerin denge ve kuvvet gelişimine anlamlı bir etkisinin olmadığı değerlendirilebilir. Öğrencilerinin dikkat testi; bölüm $1 p<0.01$, bölüm $2 p<0.01$, bölüm $3 p<0.01$ ve genel değerlendirme $p<0.01$ ön ve son test puanları arasında istatistiksel açıdan son test puanları lehine anlamlı bir fark vardır. Çalışma grubunun dikkat testi; bölüm 1 (\% 9,77), bölüm 2 (\% 7,73), bölüm 3 (\% 6,33) ve genel değerlendirme (\% 7,93) ortalama değerlerinde artış olduğu belirlenmiştir. Özmen ve Demir (2012) öğrencilerin ders dışı etkinliklere yönlendirilerek, dikkat toplama etkinlikleri, gevşeme egzersizleri ve oyunlar ile dikkat toplamalarının kolaylaştırılabileceğini bildirmektedir. Kaymak (2003) ve Karaduman (2004), bireysel ve küçük gruplar ile sınıf içi ve dışında yaptıkları dikkat toplama eğitimi çalışmaları sonucunda, ilköğretim grubundaki çocukların (2.- 5. sınıflar) dikkat toplama düzeylerinde anlamlı bir artış olduğunu saptamışlardır.

Yurdakul ve diğerleri (2012) özel olarak hazırlanmış 12 haftalık hareket eğitimi programının, 8 yaş grubu ilköğretim okulu öğrencilerinin dikkat ve hafıza gelişimleri üzerine etkili olabileceğini, Tine \& Butler (2012) fiziksel aktivitenin dikkat üzerine yararlı olduğunu destekleyen birçok çalışma olduğunu, özellikle 12 dakikalık aerobik egzersizin 10-13 yaş grubu çocukların seçici dikkatlerini geliştirdiğini bildirmektedir. Chaddock-Heyman ve diğerleri (2013) sporun 8-9 yaş grubu çocukların bilişsel kontrol ile ilişkili ön sağ ön prefrontal korteksteki değişiklikleri etkilediğini, Alesi ve diğerleri (2016) futbol oynamanın çocukların (yaş=8.8 yıl) bilişsel becerilerden dikkat üzerinde olumlu bir etkisi olduğunu bildirmektedir.

Bidzan-Bluma ve Lipowska (2018) her gün en az bir saat düzenli fiziksel aktiviteye katılan okul çağı çocuklarının daha iyi bilişsel işlev ortaya koyduklarını, Göktepe ve diğerleri (2016) spor yapan çocuklarda dikkat ve hafıza gelişimine yol açabilecek, temel hareket ve hareket örüntülerine dayanan planlanmış oyun ve benzeri etkinliklerin oldukça yararlı olabildiğini, Adsız (2010) düzenli spor yapan ilköğretim öğrencilerin spor yapmayanlara oranla \%83 daha dikkatli olduğunu, Akcınlı (2005) sekiz yaş grubu çocuklarda hareket eğitiminin dikkat ve hafıza gelişimi üzerinde olumlu etkisinin olduğunu bildirmektedirler.

Dikkat özelliği ile ilgili çalışma bulgularımız diğer araştırma sonuçlarıyla örtüşmektedir. Sonuç olarak farklııkla öğrenme yaklaşımı ile uygulanan temel hareket beceri eğitimi uygulamalarının 9 yaş (3. Sınıf) ilkokul öğrencilerinin özellikle dikkat ve motorik özelliklerden sürat gelişimi üzerine etkili olabileceği söylenebilir. Araştırmalar bizim çalışmamızda olduğu gibi fiziksel etkinliklere katılımın çocukların motorik ve dikkat gibi bilişsel özelliklerinin gelişimine olumlu etkisi olduğunu ortaya koymuştur. Bu bağlamda; okul, kulüp gibi eğitim kurumlarının idareci ve eğitmenlerin, çocukların fiziksel aktiviteye 
katılımlarının sağlanması ve sürdürülebilmesine yönelik organizasyonları gerçekleştirmelerinin, farklııkla öğrenme yaklaşımının dikkat ile sürat gibi motorik özelliklerin gelişimine olumlu etkisi yönünden fiziksel aktivite ve hareket becerilerinin uygulamasında kullanılmasının yararlı olabileceğini düşünmekteyiz.

\section{Teşekkür}

İstanbul Beykoz İlçesi Güzelcehisar Illkokulu Müdürlüğü ile Marmara Üniversitesi Spor Bilimleri Fakültesi öğrencilerinden Dilara Arslan ve Devran Arslan'a çalışmaya yapmış oldukları katkı için teşekkür ederiz.

\section{Kaynakça}

Adsız, E. (2010). Illköğretim çağındaki öğrencilerde düzenli yapılan sporun dikkat üzerine etkisinin araştıııması. $\quad$ Ege Üniversitesi, Sağlık Bilimleri Enstitüsü, Beden Eğitimi ve Spor Anabilim Dalı, Yayımlanmamış Yüksek Lisans, İzmir.

Akcınlı, N. (2005). Sekiz yaş grubu çocuklarda hareket eğitimi ile dikkat ve hafıza gelişiminin ilişkisi, Celal Bayar Üniversitesi Sağlık Bilimleri Enstitüsü Beden Eğitimi ve Spor Öğretimi Anabilim Dalı Yüksek Lisans Tezi. Manisa.

Amado, S. (1996). Farklı dikkat düzeylerinin örtük ve açık bellek üzerindeki etkileri. Yayımlanmamış Doktora Tezi, Ege Üniversitesi, İzmir.

American College of Sports Medicine (2013). ACSM's guidelines for exercise testing and prescription. Wolters Kluwer.

Bozkurt, S., Bal,M., Kırbayır, B. \& Erkut, O. (2016) fiziksel etkinlik kartlarının yer değiştirme ve dengeleme hareketleri gelişimine etkisi (beykoz ilçesi pilot ilkokul uygulaması). 14. Uluslararası Spor Bilimleri Kongresi Bildiri Kitabı. Antalya.

Campbell, D.T. \& Stanley, J.C. (1963). Experimental and quasi-experimental designs for research. Chicago: Rand McNally \& Company.

Chaddock-Heyman, L., Erickson, K.I., Voss, M.W., Knecht, A.M., Pontifex, M.B., Castelli, D.M., Hillman, C.H. \& Kramer, A.F. (2013). The effects of physical activity on functional MRI activation associated with cognitive control in children: A randomized controlled intervention. Front. Hum. Neurosci. 7, 72.

Council of Europe. Committee of experts on sports research (1988). EUROFIT handbook for the EUROFIT tests of physical fitness. Committee for the Development of Sport, Rome.

Demir, Y. M. (2009). Bilişsel bilgi işlem teorisi. M. Şahin (Ed.), Öğrenme teorileri (s. 130-182). Nobel, Ankara.

Dinçer, Ö., Çolak, E., Son, M. \& Barut,E. (2017). Thera-band ve sağlık topu ile yapılan egzersizlerin 25 metre serbest stil yüzme performansı üzerine etkilerinin incelenmesi. 9. Uluslararası Beden Eğitimi ve Spor Öğretmenliği Kongresi Özet Kitapçığı. 19-22 Ekim 2017. Antalya.

Göktepe, M., Akalın, C.T. \& Göktepe, M.M. (2016). Kayak sporu yapan çocukların dikkat düzeylerinin incelenmesi. International Journal of Science Culture and Sport, 4 (3), 722-731.

Güneş, S., Koca, F. \& Imamoğlu, O. (2019). 8 haftalık alp disiplini temel kayak eğitiminin 8-10 yaş grubu çocuklarda denge, esneklik, çabukluk ve dayanıklılı üzerine etkisi. Turkish Studies Volume 14 Issue 1, p. 381-393.

Hürmeriç, I. (2003). Illköğretim beden eğitimi öğrencilerin sağlıkla ilgili fiziksel aktivite seviyelerinin, ders içeriğinin ve öğretmen davranışlarının değerlendirilmesi. Yayımlanmamış Yüksek Lisans Tezi. ODTÜ Sosyal Bilimler Enstitüsü Beden Eğitimi ve Spor Anabilimdalı,

Ilona Bidzan-Bluma \& Małgorzata Lipowska (2018) Physical activity and cognitive functioning of children: A systematic review. International Journal of Environment Research and Public Health. 15,800 . 
İrez, S. G., Yaman, M., İrez Babayigit, G. \& Saygın, Ö. (2013). Fiziksel etkinlik kartları uygulamasının ilköğretim beden eğitimi derslerindeki öğretmen davranışları üzerine etkisi. International Journal of Human Sciences, 10(1), 1717- 1724

Karaduman, B. D. (2004). Dikkat toplama eğitimi programının Kanadalı öğrencilerin dikkat düzeyleri üzerindeki etkisi. Omep 2003 Dünya Konsey Toplantısı ve Konferansı 5-10 Ekim 2003. Kuşadasıİmir: Omep 2003 Dünya Konsey Toplantısı ve Konferansı Bildiri Kitabı. Cilt 1: 232-244.

Konrad, K. \& Gilsbach, S. (2007). Aufmerksamkeitsstörungen im kindesalter, Kindheit und Entwicklung. 16(1), 7-15.

Kaymak, S. (2003). Dikkat toplama eğitimi programının ilköğretim 2. ve 3. sınıf öğrencilerinin dikkat toplama becerilerinin geliştirilmesine etkisi. Yayımlanmamış Doktora Tezi, Ankara Üniversitesi Sosyal Bilimler Enstitüsü, Ankara.

Lapointe,T., Brassard,P., Rattray, B. \& Lachance, P.E. (2016). Physical activity counteracts the influence of mental work on blood pressure in healthy children. Physiology \& Behavior 164:102-106.

Lauth, G. W. (2004). Förderung von aufmerksamkeit und konzentration. In Lauth, G. W., Grünke, M. ve Brunstein J. C. (Eds.), Interventionen bei lernstörungen (pp. 239-248). Hogrefe Verlag, Göttingen.

MEB (2012a). Millî Eğitim Bakanlığı Talim ve Terbiye Kurulu Başkanlığı 29.08.2012 tarihli ve 139 sayılı kararı.

MEB (2012b). Oyun ve fiziki etkinlikler dersi öğretim programı (1-4. Sınıflar). TTKB Devlet Kitapları Müdürlüğü Basımevi. Ankara.

Özbar, N. (2018) Çocuklarda Psikomotor Gelişim. Ergün Yayınevi. Ankara

Özdoğan, B. (1999). Seminer ders notları. Ankara Üniversitesi, EBF, Ankara.

Özmen, K.S. \& Demir, Ö. (2012). Illköğretim öğrencilerinin dikkat toplama sürecine ilişkin görüşlerinin incelenmesi. ç.Ü. Sosyal Bilimler Enstitüsü Dergisi, 21(1),135-154.

Schöllhorn, W. (2015) Avrupa Birliği Erasmus+" Eğitim Programları Farklııkla Öğrenme Semineri. 10-11 Aralık Marmara Üniversitesi Beden Eğitimi ve Spor Yüksekokulu, İstanbul. Seminer Sunum Notları.

Schollhorn, W. I., Hegen, P., \& Davids, K. (2012). The nonlinear nature of learning: A differential learning approach. The Open Sport Science Journal, 5, 100-112.

Schöllhorn W.I., Mayer-Kress G., Newell K.M. \& Michelbrink M. (2009) Time scales of adaptive behavior and motor learning in the presence of stochastic perturbations. Human Movement Sciences. Journal, 28(3):319-33

Tine, M.T. \& Butler, A.G. (2012). Acute aerobic exercise impacts selective attention: An exceptional boost in lower-income children. Educational Psychology, 32, 821-834.

Tohumat, M. \& Arabacı, M. (2017). Halk oyunları çalışmalarının çocukların fiziksel uygunluklarına etkisi. İnönü Üniversitesi, Beden Eğitimi ve Spor Bilimleri Dergisi, 4(1),16-27.

Yıldız, S. (2013). Çocuk tenisçilerde fonksiyonel antrenman yaklaşımı. Yayımlanmamış Yüksek Lisans Tezi. Marmara Üniversitesi Sağlık Bilimleri Enstitüsü.

Yılmaz, M.O. \& Bozkurt, S. (2017). Oyun ve fiziki etkinlikler dersinin ilkokul öğrencilerinin motorik özelliklerinin gelişimine etkisi. Marmara University Journal of Sport Science, 2(2), 49-55.

Yin Z. \& Moore J.B. (2004). Re-examining the role of interscholastic sport participation in education. Psychological Reports, 94(3), 1447-1454.

Yurdakul, N.A., Çamlıyer, H., Çamlıyer, H., Karabulut, N. \& Soytürk, M. (2012). Sekiz yaş grubu çocuklarda hareket eğitiminin dikkat ve hafıza gelişimine etkileri. Selçuk Üniversitesi Beden Eğitimi ve Spor Bilim Dergisi,14(1): 103-108.

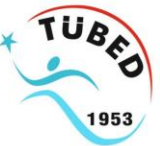

All rights reserved by Turkish Association of Physical Education Teachers Tüm hakları Türkiye Beden Eğitimi Öğretmenleri Derneği'ne aittir. 